\title{
BRIDGING THE GAP
}

\section{Introduction}

The US Veterans Administration (VA) National Cemetery Administration's Veterans Legacy Program seeks to commemorate the lives of the nation's veterans by promoting education and research among university and K-12 students (US Department of Veterans Affairs, 2021a). Previously, work has been done by the

University of Central Florida and South Dakota to create educational content for K-12 students regarding writing and history about veterans (US Department of Veterans Affairs, 2021b). A gap had been created for

technological education and how these technologies can be used in the National Cemeteries to promote the memorialization of the nation's veterans. It was

determined after reviewing this leading curriculum that a gap exists. This gap in educational content for the VA led to the acknowledgment that this educational gap exists also in the public school system-many K-12 students, particularly those in rural areas, often dd students, particularly those in rural areas, often do not have access to the science, technology, engineering, and mathematics (STEM) concepts demanded in today's evolving workplace.

Texas A\&M researchers worked in partnership with the VA to extend the memorialization of Texas A\&M Aggie veterans enshrined in the Houston National Cemetery though the Aggie Legacy Project. This was

accomplished using advanced technologies to create a 3D module of the cemetery, an artificial intelligence to read and record headstone conte read and record ceadsons, and biographical hibutes to team also created educational content designed to introduce K-12 students to these technologies with the intent to help students explore STEM career paths early, allowing time to make informed decisions regarding future career opportunities.

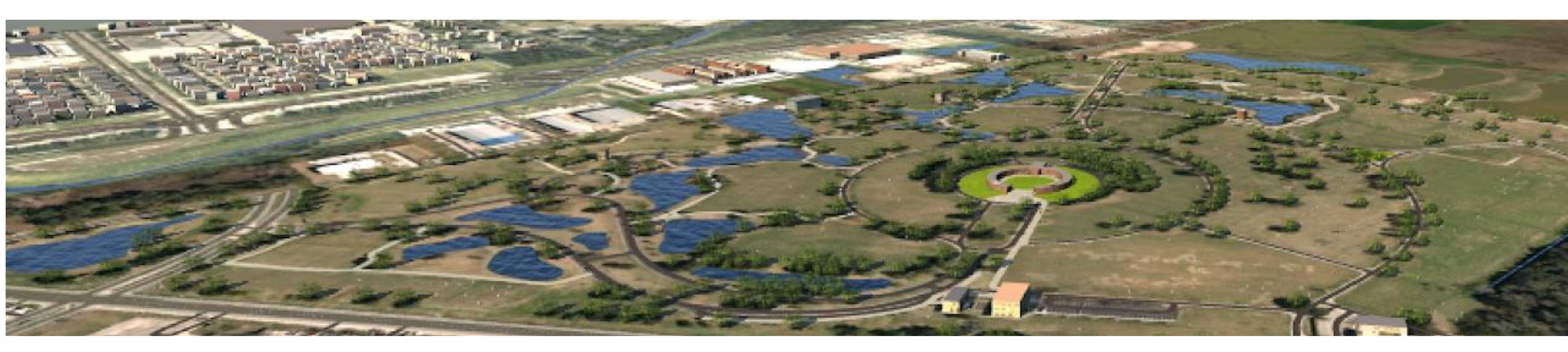

\section{Methods}

The goal of the educational modules created in the Aggie Legacy Project is to improve the alignment of curriculum to theory and practice. Traditional educational methods typically rely on rote learning. Using this method, students are promoted to memorize and reproduce information rather than understand and apply knowledge. By learning and doing at the same time, students take charge of education and can make connections to real world applications. The research team collaborated with a group of volunteer students and staff of Klein ISD for feedback and input.

Online educational modules developed in this project contain interactive activities (like matching terms and definitions and determining if statements are true or false) and mini-quizzes during the module to promote student interaction and attention, an interactive experiential learning lab to help students make connections to real applications, and a final quiz to ensure information retention. The labs in the educational modules are based on technology applications used in the Aggie Legacy Project, like creating a 3D model of a headstone and testing the accuracy of a phone's built-in GPS. These labs are intended to provide students a sense of creating a tangible impact on the community. 

\section{Implementation}

The educational modules are designed for continuous improvement. Their online nature allows for and promotes dynamic updates to the content, easy for instructors to modify as curriculum changes.

Improvement is a serious consideration for instructors as much technologically-based content becomes outdated rapidly as times progress. Students are promoted to learn and then test out their knowledge in tactile application with appropriate assistance from instructors when needed.

\section{Example}

The following images are example slides from one online module developed to teach students about the National Cemeteries, field data collection, and historical research. The module and slides are designed to be interactive and self-paced.
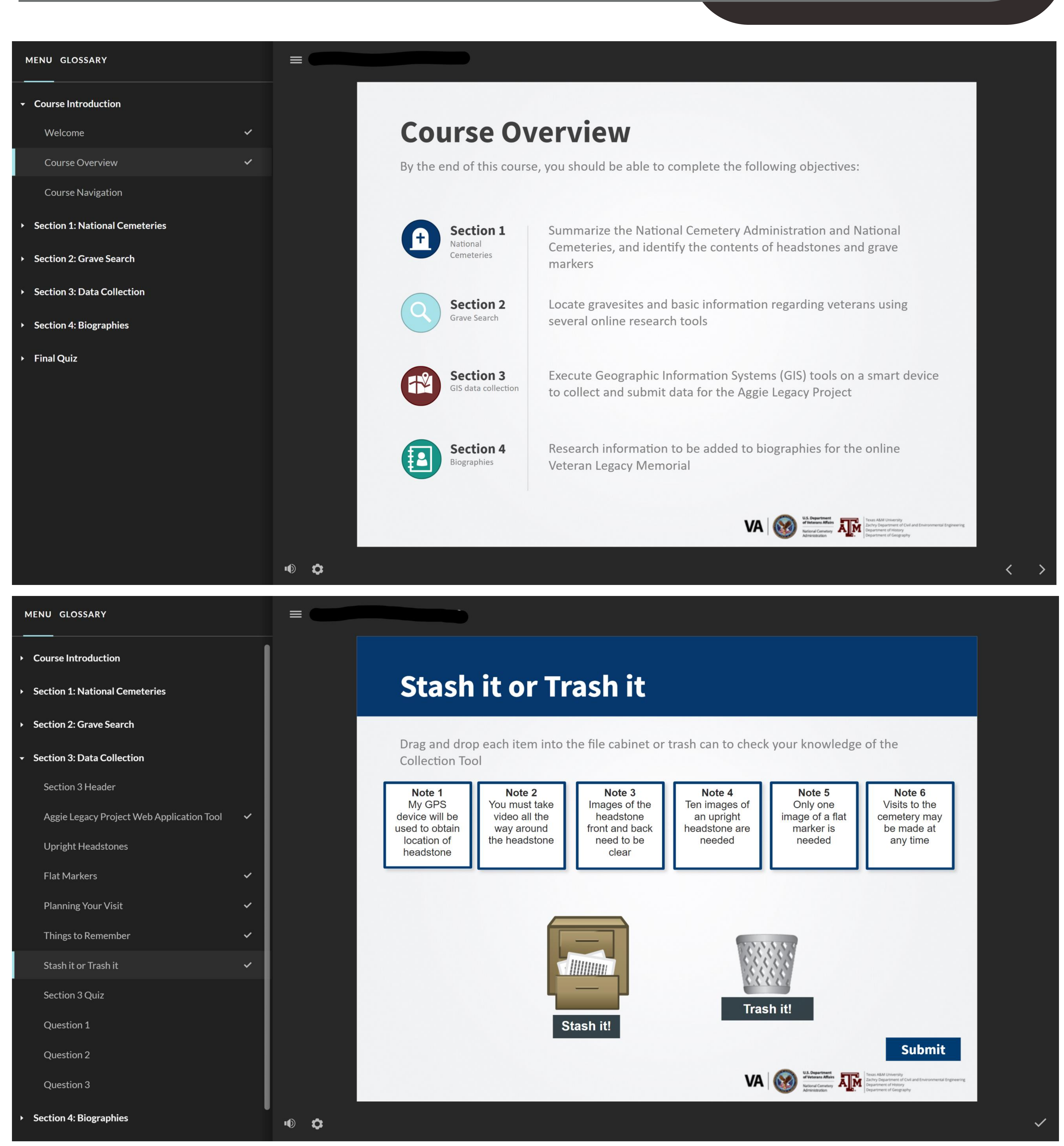

\section{Broader Impact}

The broader impact of this research is to create multimodality learning modules to improve student's knowledge and skills, resulting in improved engineers and reduced risk. Introducing engineering content at an earlier stage helps to eliminate the gap between knowledge and application. 